\title{
Cultural Attitudes of Romanian Youth
}

\author{
Bob Ives \\ University of Nevada Reno \\ E-mail: rives@unr.edu \\ Kathryn Obenchain \\ Assistant professor \\ University of Texas \\ E-mail:KMObenchain@austin.utexas.edu \\ Eleni Oikonomidoy \\ Assistant Professor \\ Department of Educational Specialties, University of Nevada \\ E-mail: eleni@unr.edu
}

\begin{abstract}
A variation of the Bogardus scale on social distance was implemented to examine the cultural attitudes of Romanian youth about minorities in Romania. The results indicated that the greatest social distance was reported towards members of the Rroma minority with members of the Hungarian minority following. The least social distance was, not surprisingly, associated with members of the Romanian majority. The findings of this study are examined in light of their implications for teacher education, in the continuously changing sociopolitical landscape of Romania.
\end{abstract}

Keywords: Cultural attitude, Romanian youth, Pre-service teacher 
Teacher education programs prepare pre-service teachers to effectively teach their future students the knowledge, skills, and dispositions required to successfully integrate into multiple social spaces, whether they be local or global (see, for example, www.aacte.org and www.ncate.org). Given that most societies in the European Union (EU), as well as the student populations within them, are quite diverse in terms of ethnicity, nationality, and culture, such a task becomes especially daunting for educators who have traditionally operated out of monocultural frameworks (Gogolin, 2002). Identifying and aiming to deconstruct negative dispositions among pre-service teachers is not an easy task. Dispositions include beliefs (and subsequent practices) about the purpose of school, the role of teacher, parent, and student, as well as beliefs about whom students are as individuals and learners, how they should be taught, and what they can accomplish (Walker-Dalhouse \& Dalhouse, 2006). Because pre-service teachers enter the classroom with preconceived notions about the world and the people who inhabit the world, they judge their students (Bennett, 2007; Gay, 2000; Howard, 1999; Locke, 2005). This judgment reflects attitudes about race, ethnicity, gender, religion, disability, etc. Teacher education programs in many countries within the EU and abroad (e.g., Greece. Australia, the Netherlands, Cyprus, Hong Kong, United States) are addressing these issues. While some nations have well-established classes, or entire programs, that emphasize multicultural or intercultural education that aim to help pre-service teachers recognize, examine, and often reconstruct, their pre-conceived notions, other nations are discussing or are in various stages of the implementation of classes and programs (Damanakis, 2005; Gay, 2000; Leeman \& Reid, 2006; Panayiotopoulos \& Nikoliadou, 2007. Westrick \& Yuen, 2007). An essential and early step in this process is the identification and recognition of those pre-conceived notions (Subedi, 2006). In our increasingly interdependent world such a process should be implemented both within and across national borders. The focal society in this study is Romania, a country that has recently joined the EU. Noting the tremendous changes in Romanian society since the 1989 revolution, including all levels of education, the purpose of this study was to examine current attitudes of the majority (Romanians) towards minorities. Specifically, the attitudes of Romanian secondary school students in a pedagogical track and pre-service teachers in the Transylvanian region of Romania were examined. Noting the long history of ethnic tensions in Romania and the surrounding region, and the role of education in reducing tensions, it is important to first understand the existing attitudes of youth, particularly those who may be teachers.

\section{Relevant Literature}

\subsection{Geographical and Historical Context}

Romania is located in Southeastern Europe, on the north side of the Balkan Peninsula and has over 20000000 citizens. It is in the process of undergoing rapid socio-political and economic transformation. From 1965 up until the revolution of 1989, Romania experienced totalitarian communist control under the rule of the dictator Ceauşescu. During these years, a strong assimilationist agenda was promoted and any open discussion of ethnic, religious, or economic diversity (private property was not allowed) in the country was forbidden (Cozma, Cucos, \& Momanu, 2000; Linden \& Pohlman, 2003). For example, the Rroma were officially non-existent (Crowe, 2008). 
Upon the transformation of its political regime from a dictatorship to a constitutional democracy, and the lifting of the iron curtain, Romania was found to have the worst living standards in the region (Linden \& Pohlman, 2003), and there were negative reports related to the support of minority and human rights (Dianu, 1997). Despite the high expectations of Romanians for a quick economic restructuring after the fall of communism, the living standards dropped by $35 \%$ in the few years after the 1989 revolution (Gallagher, 1997). Since that time, the economy has seen some strengthening, but it still carries a substantial budget deficit which has a destabilizing effect (Moldovan \& Lazar, 2009). Nevertheless, the fall of the 'communist wall' in Romania resulted in an increased involvement in the international, particularly European, economic and political space. Romania joined the North Atlantic Treaty Organization (NATO) and began negotiations with the European Union soon after the transformation of its political regime. Romania joined the European Union (EU) in January 2007. The impact of the EU's policies however, goes back in time and can be seen in the legislation that was passed to satisfy the conditions for membership. Although some assert that "the minority protection and nondiscrimination legislation in Romania seem to have been in large triggered by external conditionality and rule promotion, especially by the EU. However, externally driven rule adoption was limited to minority protection concepts that resonated with Romanian institutions..." (Schwellnus, 2005, p. 59).

In 1993, Romania joined the Council of Europe and signed the European convention on the protection of Human Rights and Fundamental Freedoms (Gallagher, 1997). Recent attempts have been implemented to improve the relationships between the majority Romanian population and the numerous minorities (Butuca, 2003), including the visible minorities of the Hungarians and the Rroma. It has been argued that during the process of democratization in the transitional post-communist era, Romania has succeeded in maintaining civil order while some of its neighboring countries in the Balkans experienced violent ethnic conflict (Johnson, 2002). Although this success has been attributed to external forces (such as interventions by the European Commission) by some (Chiva, 2006), and internal forces by others (Johnson, 2002), it seems that an atmosphere of tolerance of minority populations is evident in the country. This projected image to the international community is problematized by Cajvaneanu (2004), who argues that tolerance does not equal integration or equal status. Integration and equal status imply the ability of the majority and minority populations to interact positively in professional and personal settings. How comfortable one is with those who are different is a factor in this integration.

\subsection{Social Distance}

Social distance measures address how comfortable one feels at various levels of closeness with individuals of different groups (Bogardus, 1933). For example, these groups may represent race and/or ethnic groups (Rapp, 1982), disabilities groups (Ives \& Howell, in press), or those with mental illness (Adewuya \& Makanjuola, 2005). Individuals categorize those in their social environment as being members of a number of groups, some of which are considered in-groups (a group to which the person doing the categorizing perceives her or himself being a member of) or out-groups (Transue, 2007). Although some group memberships may be fluid and temporary (Chasteen, 2005), such as college student or 
American tourist, stronger identification with a group correlates with more positive feelings toward other members of that particular group (i.e., other members of the in-group). Conversely, feelings are less positive for members of an out-group and may result in increased levels of discomfort (i.e., less tolerance, greater social distance) when faced with interacting with members of an out-group. Individuals often identify in-group and out-group status related to ethnicity, nationality, and race. Discomfort with an out-group is manifested in a variety of ways, including prejudicial attitudes and discriminatory practices. These attitudes and practices occur at both individual and institutional levels. Consistent with previous research, a recent Swedish study (Snellman and Ekehammar, 2005) that surveyed university psychology students on a social distance measure found that there was more tolerance for members of the in-group than tolerance for members of the out-group. While these results focus on the tolerance of individual university students, there are broader consequences. On a societal level, support (e.g., voting) for social and political rights for minorities is affected by the group's status as an in-group or out-group. These varying levels of support may further privilege in-groups, as well as further marginalize out-groups.

Evans and Need (2002) studied several former Communist nations in eastern Europe, hoping to explain ethnic polarization and attitudes toward minority rights. The study examined both majority and minority attitudes through four different categories: insecurity, perceived threat, social differences, and social distance. They found that social distance was the best predictor for differences among individual respondents. The more discomfort (e.g., the greater the social distance) perceived by the respondents, the less willing they were to support social and political rights for minorities. Romania reported the fourth highest (most polarized) polarization score out of the 13 nations studied. So, while Romania's transition from dictatorship to democracy saw limited violent ethnic clashes, ethnic tensions, as evidenced by polarization, do exist.

\subsection{Minorities in Romania}

The status of the Hungarian and Rroma minority groups in Romania has been shaped by various events in the distant past as well as the most recent history of the country within its surrounding context. The vastly different status of the two groups in Romanian society warrants separate analysis. In the most recent history, during the rule of Ceauşescu, the status of the Hungarian minority lowered significantly across the country and most specifically in the Transylvanian region (Veres, 2006). According to estimates, the size of the Hungarian population in Romania was 1.6 million in 1990 (Chiva, 2006). The nature of the relationships of the Hungarian minority with the majority Romanian population is connected to the country of origin (Hungary). According to Dianu (1997), violent ethnic tensions with the Hungarian minority in the Transylvanian region of Romania arose when in 1990 Hungarians celebrated the Hungarian National day. The same author states that "[i]n the city of Cluj-Napoca, the local council members... took a series of aggressive actions against the Hungarian community, evicting some ethnic organizations and publications from their premises, and banning the use of bilingual signs (p.8)." At a different level, an act for special rights of the Hungarian minorities living in the neighboring countries, which was promoted by the Hungarian government, was perceived with strong resistance from Romania. It was the 
mediation of the European Commission that alleviated the tensions (Chiva, 2006). Upon the recognition of Romania as an associate member of the European Union, the Council for National Minorities was created in an effort to ameliorate some of the tensions that existed. In addition, in 1996 Hungary agreed to abandon its claims for territory in Romania, an event that seemed to provide some improvement to the relationship between Romanians and Hungarians at the political and legal fields. Hungarian representation in political institutions in Romania coupled with the real or imaginary support from Hungary seemed to work as safety valves protecting the Hungarian population from further marginalization within Romanian society. These events furthermore facilitated recognition of Hungarians' status in Romania, which translated into the establishment of Hungarian-language schools and universities (Ram, 2006). The attention to the needs of the Hungarian minority by the Romanian government has intensified in the last years, despite the occasional opposition (Ram, 2006).

The same is not true for the Rroma (also referred to as Gypsies) minority in the area despite the fact that it is one of the oldest and most numerous minorities (Cozma, Cucos \& Momanu, 2000). Kruczek-Steiger and Simmons (2001) write that "In Europe, the Rroma probably because they are a people without an ethnic territory or a national state of their own, frequently qualify for being the most hated of all ethnic groups" (p. 281). Arayici (1998) and Crowe (2008) assert that Rroma are often perceived as social outcasts and are victims of historical and current discrimination, prejudice, and persecution. The vulnerability of the Rroma population is evident in Romania as well, and although status and integration have seen some positive movement in very recent years (e.g. 2006-2007), Rroma continue to be extremely marginalized (Filipescu, 2009). While Romania has the largest Rroma population in Europe (estimated at around 2 million), the status of the Rroma continues to be very low in the economic, political and social spheres (Crowe, 1999; Ram, 2006; Rat, 2005). Crowe (2008) believes that the Rroma may struggle more in Romania because of both their numbers and their history of enslavement in Wallachia and Moldavia, two principalities that are part of the current nation of Romania. In addition, having no exposure or limited exposure to education in post-communist Romania further hampers Rroma's occupational opportunities and reproduces the cycle of poverty and marginalization (Pogany, 2006). Further, it has been proposed that in Central and Eastern Europe, the Rroma provide societal 'scapegoats,' and are being blamed for the increase in criminal activity, furthering their distance from the majority populations (Pogany, 2006).

Efforts are being implemented to counteract some of the negative forces that impact the status of this ethnic group. The decade 2005-2015 has been declared as the "Decade for Rroma inclusion." The national strategy for the improvement of the condition of the Rroma ranges from representation in the local governments, to consultancy roles and educational and cultural enrichment programs. However, despite the increased governmental attention (encouraged by international influences) on the violence towards the Rroma, negative public attitudes toward the Rroma are quite strong (Crowe, 1999; Pogany, 2006). Crowe writes that, "a strong atmosphere of mutual suspicion and mistrust continues between Roma and non-Roma” (p. 64). This climate does not escape educational institutions, housing policies 
and employment (Ram, 2006). Abuse of Rroma students in schools takes place at multiple levels, from segregationist policies (special education classes) to abuse by the teachers, and neglect by classmates and even parents of the majority group (Cahn, et al., 1998; Cozma, Cucos, \& Momanu, 2000; Crowe, 2008).

Despite the concerned efforts at multiple levels, Tibbitts (2001) reminds us that, "in countries undergoing transition, cultural and educational processes can lag behind" (p. 29). Endorsing education for all children has been alive since the initial conception of Romania. Nevertheless, the challenges are different now that Romania's political structures promote the creation of an educational system that is open to the full inclusion of minority groups.

This study took place in the midst of political, economic, social and cultural transitions in Romania. Its goal was to shed light on the perceived social distance from members of the majority to members of the minorities at both levels - within the country and in a more global level. In addition to examining the social distance attitudes of the predominant minority groups in Romania (e.g., Hungarians, Rroma), social distance attitudes toward Americans, persons of Hispanic, African, and Native American origins were also examined. Given that Romania has opened up its doors to the world it was considered significant to expand the scope of this study beyond the boundaries of the country. The research questions for this study were: 1) How are the cultural groups ordered in terms of social distance by Romanian future educators? 2) Does familiarity with people in other groups predict lower social distance from people in those groups? 3) Do social distance patterns differ when comparing in-groups versus out-groups?

\section{Methods}

\subsection{Participants}

All of the 95 participants were native Romanian students who were planning careers in the field of education. The average age of participants was 19.02 years $(\mathrm{SD}=2.50)$. As is typical of programs in the field of education, there were far more females (87) than males (8). Every student who was recruited completed the instrument. One instrument from a high school student was not included in the data analyses because some of the items were skipped.

The high school students $(\mathrm{n}=54)$ ranged in age from 15 years and 1 month to 17 years and 4 months. They attended a pedagogical high school in Cluj-Napoca, Romania. Upon completion of the program, these high school graduates would be qualified to teach children in early elementary grades. The pedagogical high school program was being phased out of the Romanian educational system, so these students were among the last to become teachers through this program. The curriculum at the pedagogical high schools is a national curriculum, and all of the students were local to the city, so this group should be reasonably representative of other students participating in similar programs across the country.

The university students, also in Cluj-Napoca, were enrolled in several different undergraduate programs leading to careers as general education teachers, educational consultants, or school administrators at Universitatea Babes-Bolyai (UBB). The university students $(n=41)$ ranged in age from 19 years and 5 months to 22 years and 5 months. They were planning careers in a 
variety of positions, including classroom teachers in specific content areas, school psychologists, speech therapists, and pedagogical consultants. The university is one of the largest in the country, with well over 40,000 students. UBB also offers a wider range of specializations than any other university in the country (Universitatea Babes-Bolyai, 2007), with separate programs in three official languages - Romanian, Hungarian, and German. In a 2005-6 national survey, the faculty at UBB ranked second in the country in publications per faculty member (Ad Astra, 2007). These credentials have helped the university to a strong regional reputation, with students drawn from across the country as well as neighboring countries such as Hungary and Moldova, and many Erasmus students from across Europe. Participants in this study all self-identified as ethnic Romanians, and they should be representative of strong students from across the country in education related fields.

\subsection{Instrument}

We developed a questionnaire to assess social distance relative to various ethnic, national and cultural groups based on the Bogardus Scale of Social Distance (BSSD) (Bogardus, 1933), hereafter referred to as the Romanian Culture Distance Scale (RCDS). The English language version of the RCDS was reviewed for culturally appropriate language and concepts and translated into Romanian by a Romanian university teacher educator. Participants rated each item on the RCDS on a five-point scale, with ' 1 ' meaning very uncomfortable and '5'meaning very comfortable. A sample item read, "A Hungarian person as a dinner guest in your home." Each item referred to one of seven cultural groups and one of nine social relationships. Every cultural group was matched with every social relationship to yield a total of sixty-three items. The seven cultural groups were Romanian, Hungarian, American, Rroma, Hispanic origin, Africa origin, and, Native American. Each of these groups was paired with each of the following nine social relationships: living in your country, visitor in your home town, occasionally talk to, next door neighbor, dinner guest in your home, close friend, classmate or co-worker, working in a store where you shop, and marrying into your family. Pairing each of the seven cultural groups with each of the nine relationships yielded sixty-three items that were ordered randomly so that participants would be less likely to recognize sequential patterns in the instrument and respond according to those patterns.

The RCDS began with a page of questions to gather some demographic data and determine how much personal experience each participant had with persons of the cultural groups represented in the study. Demographic data included age, grade level, and sex. For each of the seven cultural groups, participants were asked if they were a member of the group, had a friend or family member who was a member of the group, or had ever met anyone who was a member of the group. Each of these items were scored as one if the response was positive, and zero if the response was negative, for a maximum total of three points for personal familiarity with each group.

\subsection{Procedures}

After making prior arrangements with the school and the classroom instructor, the RCDS was administered to classroom groups ranging from twelve to twenty-eight students. All students in each class were invited to participate and informed of their right to refuse. A copy of the 
RCDS was distributed to each student in the class, instructions were reviewed, and students were given no time limit for completing the RCDS. The completed instruments were collected after students were finished with them.

Perhaps the most significant challenge presenting data from a new instrument is the need to provide evidence for reliability and validity. Variations on the BSSD, such as the RCDS presented in this article are backed by more than 70 years of consistent use for research the social sciences. In this sense, every variation of the BSSD is a new instrument based on a well-established model. Some of the recent variations have included as many as five of the seven original relationships chosen by Bogardus (e.g. Parrillo and Donoghue, 2005), while others have included only one (e.g. Batiuk, Boland, and Wilcox, 2004). These variations have investigated attitudes towards differences as diverse as mental illness ( Dietrich, 2004; Van Dorn, Swanson, Elbogen, \& Swartz, 2005), race (Raden, 1998; Randall and Delbridge, 2005), social deviance (Kunz and Kunz, 2001), middle school cliques (Batiuk, Boland, and Wilcox , and disabilities (Rimmerman, Hozmi, \& Duvdevany, 2000).

Some estimate of reliability may be developed by analyzing data from a new instrument to see if the results are consistent with the intended structure of the instrument. For example, measures of internal consistency, such as Cronbach's alpha or split-half reliability, are appropriate for instruments in which all the items are intended to measure the same construct. For our RCDS, if we assume that all items measure the same broad construct of social distance towards cultural groups, then we would predict a high level of internal consistency. We did run a Cronbach's alpha for our data. This analysis yielded a coefficient of .971, which is quite high.

Weinfurt and Moghaddam (2001) offered an alternative approach for evaluating the validity of variations on the BSSD. They pointed out that the BSSD assumed that more intimate relationships will be related to greater social distance than relationships that are less close. To explore the validity of this assumption as evidenced in our data, we first ranked each social relationship based on the sum of scores across all culture categories. The sum of those rankings had a minimum of seven and a maximum of thirty-five. Means and standard deviations for these sums are reported in Table 1 in order from highest comfort level (lowest social distance) to lowest comfort level (highest social distance). 


\section{Macrothink}

International Journal of Education

ISSN 1948-5476

2010, Vol. 2, No. 1: E4

Table 1. Means and standard deviations of summed rankings by personal relationship

\begin{tabular}{lc}
\hline Personal Relationship & Mean (SD) \\
\hline Visitor in your home town & $31.60(3.79)$ \\
Living in your country & $31.03(3.94)$ \\
Close friend & $30.34(3.71)$ \\
Classmate or co-worker & $30.18(4.00)$ \\
Working in a store where you shop & $30.02(4.67)$ \\
Next door neighbor & $29.99(3.93)$ \\
Occasionally talk to & $29.98(4.20)$ \\
Dinner guest in your home & $29.16(4.50)$ \\
Marrying into your family & $26.95(5.17)$ \\
\hline
\end{tabular}

To estimate the extent to which each personal relationship was separated from the others in terms of overall social distance, we ran one-tailed paired t-tests for all possible pairs of personal relationships based on the order of means listed in Table 1. Table 2 reports the significance levels for each of these t-tests.

Table 2. Significance values for t-tests of summed rankings by relationship

\begin{tabular}{|c|c|c|c|c|c|c|c|c|}
\hline & Living & Friend & Class & Worker & Neighbor & Talk & Dinner & Marry \\
\hline Visitor & .000 & .000 & .000 & .000 & .000 & .000 & .000 & .000 \\
\hline Living & & .000 & .000 & .000 & .000 & .000 & .000 & .000 \\
\hline Friend & & & .172 & .120 & .0056 & .059 & .000 & .000 \\
\hline Class & & & & .268 & .149 & .170 & .000 & .000 \\
\hline Worker & & & & & .456 & .448 & .000 & .000 \\
\hline Neighbor & & & & & & .480 & .000 & .000 \\
\hline Talk & & & & & & & .000 & .000 \\
\hline Dinner & & & & & & & & .000 \\
\hline
\end{tabular}

Table 2 indicates relatively poor discrimination among the five middle relationships of close 


\section{Macrothink

friend, classmate or co-worker, working in a store where you shop, next door neighbor, and occasionally talk to. In general these data confirm the assumption that less intimate relationships, such as visitor in your home town, will yield higher levels of comfort than more intimate relationships, such as marrying into one's family.

\section{Results}

\subsection{Research Question 1}

The first research question for this study was, "How are the cultural groups ordered in terms of social distance by Romanian future educators?" To estimate differences in social distance from different cultural groups, the rankings for each cultural group were summed across all of the nine social relationships. Because rankings ranged from one to five, the sum of these rankings had a minimum of nine and a maximum of forty-five. Higher rankings indicate greater comfort or less social distance. Table 3 reports the means and standard deviations for each of the groups. Groups are listed in the table in order from highest to lowest mean score.

Table 3.: Mean social distance scores for each of the cultural groups

\begin{tabular}{lr}
\hline \multicolumn{1}{c}{ Cultural Group } & Mean Score (SD) \\
\hline Romanian & $43.74(2.643)$ \\
Hispanic Origin & $42.08(4.598)$ \\
American & $41.86(4.363)$ \\
African Origin & $39.62(6.864)$ \\
Native American & $39.46(6.687)$ \\
Hungarian & $36.11(9.219)$ \\
Rroma & $26.37(10.123)$ \\
\hline
\end{tabular}

To estimate the extent to which each cultural group was separated from the others in terms of overall social distance, we ran one-tailed paired t-tests for all possible pairs of disabilities based on the order of means listed in Table 3. Table 4 reports the p-levels for each of these t-tests. 
Table 4. Significance levels for pairwise comparisons of social distance between cultural groups

\begin{tabular}{|c|c|c|c|c|c|c|}
\hline & Hispanic & American & African & Native & Hungarian & Rroma \\
\hline Romanian & .000 & .000 & .000 & .000 & .000 & .000 \\
\hline Hispanic & & .330 & .000 & .000 & .000 & .000 \\
\hline American & & & .000 & .000 & .000 & .000 \\
\hline African & & & & .675 & .000 & .000 \\
\hline Native & & & & & .000 & .000 \\
\hline Hungarian & & & & & & .000 \\
\hline
\end{tabular}

Table 4 indicates relatively poor discrimination between social distance from people of Hispanic origin and Americans, as well as between people of African origin and Native Americans. All other comparisons are highly significant.

\subsection{Research Question 2}

The second research question for this study was, "Does familiarity with people in other groups predict lower social distance from people in those groups?" To address this question we correlated the total level of experience each participant reported for each group with the social distance rankings each participant assigned to that same group summed across relationships. None of these correlations reached conventional levels of significance.

Given the possibility that close relationships with members of other groups maybe better predictors of tolerance than overall experience with other groups, we also ran a post hoc analysis correlating the tolerance levels for each group with whether or note each respondent reported having a close friend or family member in that same group. This was not possible for the Romanian group, as every respondent reported a Romanian close friend or family member, so there was no variance in these data. For the other six groups none of these correlations reached conventional significance levels, providing no support for the prediction that close relationships would predict greater tolerance.

\subsection{Research Question 3}

The third research question for this study was, "Do social distance patterns differ when comparing in-groups versus out-groups?" Figure 1 shows the mean social distance levels reported for all of the seven culture groups included in our instrument. The first three, Romanian, Hungarian, and Rroma, are considered in-groups in Romania because they either constitute the majority or a substantial and officially recognized minority. The other four groups do not meet either of these criteria. Mean differences between all three of the in-groups were all significant with large effect sizes. Visual analysis shows these differences 
to be substantial as well. In contrast, although some of the mean differences between out-groups were also statistically significant, the effects sizes are much smaller, and the overall range of these means is relatively small, ranging from 39.36 to 42.08 .

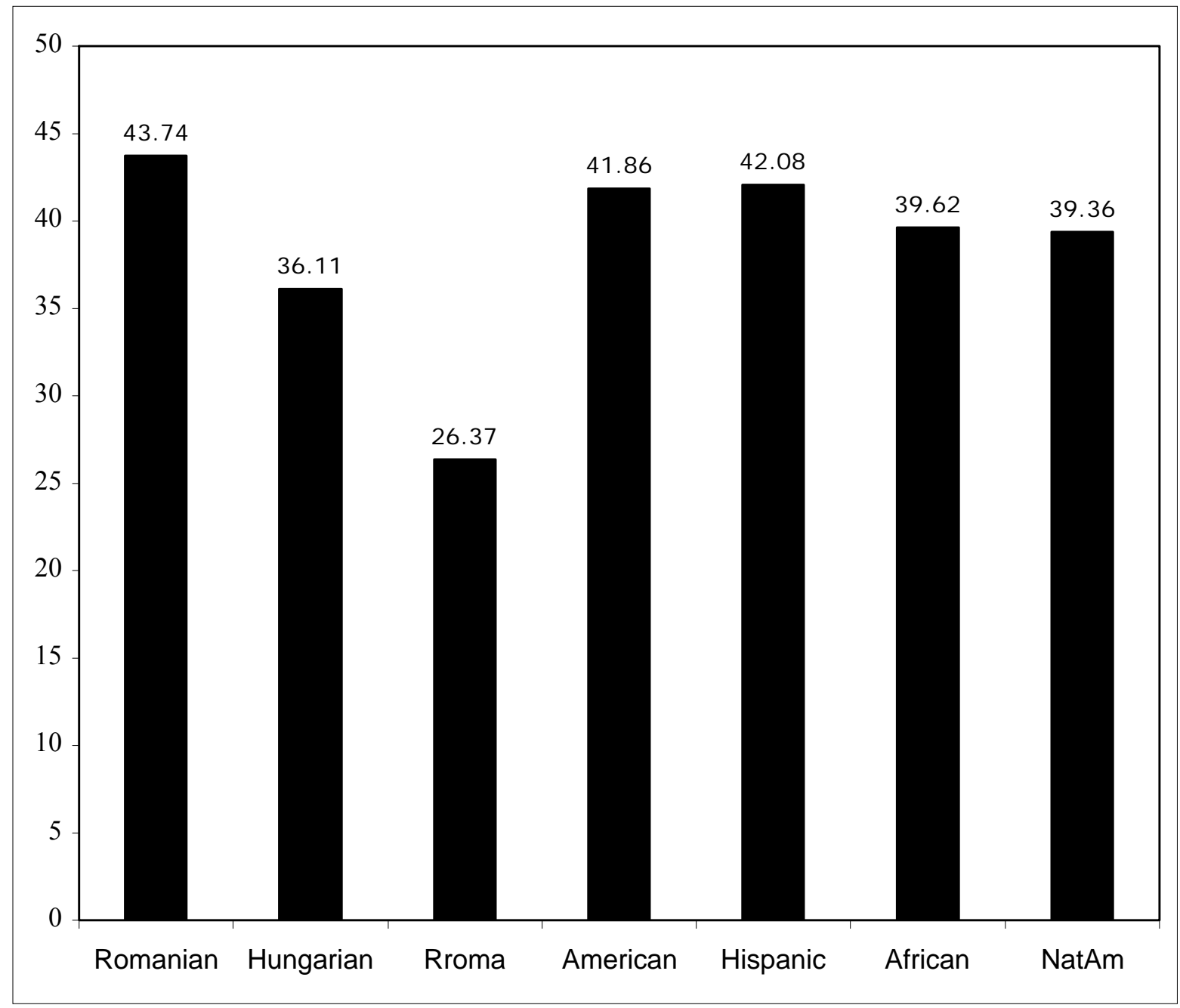

Figure I. Mean social distance scores for Romanian pre-service teachers across seven cultural and ethnic groups

\section{Discussion}

This study has yielded evidence that Romanian pre-service educators report the least social distance with respect to Romanians, and the most social distance with respect to Rroma. These results are not surprising given the social history in Romania. More surprisingly, we found no consistent evidence that greater contact with members of other groups was related to reduced social distance. These results will be discussed in the context of Allport's (1954) intergroup contact theory and more recent elaborations on that theory. Finally, our results do show that Romanian pre-service educators reported a wider range of social distance across groups that are well represented within their country than they do for other groups that are not well represented within Romania.

Our results are consistent with the assumption that closer relationships will yield less social 
distance. The results are also consistent with research showing that the Rroma people suffer from great discrimination. These results suggest that our RCDS has adequate validity for this kind of research and can be used appropriately for follow-up studies and related research. Of course additional research using this instrument could strengthen confidence in the validity of results.

A limitation or this study comes from the lack of definitions for the various groups. We did not define the groups for the participants. Instead, we asked them to rate each item based on their own views. In one sense this is exactly what we intended. We were interested in investigating the attitudes our participants held towards these groups based on their own beliefs. However, this openness may have lead to ambiguity. Some groups, such as Rroma, may have been more likely to lead to clear reactions based on shared stereotypes and personal experiences. This group is likely to also be seen as racially distinct. By contrast, Americans as a group may not evoke a strong common view. Participants will have had very limited personal experiences with Americans, although they certainly know of Americans through mass media and academic studies. These representations may not give a well-defined representation of Americans. Results may have also been influenced by the fact that a group of Americans were conducting the research.

Our results and the limitations of the study suggest several directions for future research. One would certainly be to identify a more representative sample of high school students in Romania. Systematic replication with students who aspire to careers outside the field of education, as well as working adults and younger children is in order. Given the results we have for students who identify themselves as Romanians, comparison of these findings with findings from representative samples of other groups (e.g. Hungarians, Rroma) in Romania should yield some interesting patterns. In addition, sampling of groups outside of Romanian but in the instrument (e.g. Native Americans, African Americans) would help to confirm our finding that social distance patterns for in-groups are different from those for out-groups.

\subsection{Implications for Teacher Education}

As Romania has transitioned from communist state to independent republic and now to membership in the European Union, its long history of ethnic group tensions continue to be addressed. Numerous institutions, from national political systems to individual schools, view prejudice reduction as a goal. In light of the findings of this study related to attitudes toward minorities, and in particular the Rroma, as well as the available literature, teacher education programs may want to explore ways to incorporate prejudice reduction as a component of multicultural education (Banks \& Banks, 2006) into the university teacher education curriculum. While specific work is being done with youth and with teachers in Romania (see for example, the Berghof Research Center for Conflict Management at http://www.berghof-center.org/uploads/download/oldp_romania_e.pdf, the Intercultural Institute of Timisoara at http://www.intercultural.ro/en/index.html, and the Open Society Foundation-Romania at http://www.osi.hu/iep/minorities/Countries/Romania.htm), there is room for additional attention to the issues. One way to develop prejudice reduction curriculum is through Allport's (1954) intergroup contact theory. It is a well known and 
extensively researched (Ellison \& Powers, 1994; Pettigrew, 1998; Pettigrew and Tropp, 2000) and reviewed (Forbes, 1997; Jackson, 1993; Patchen, 1999) theory addressing intergroup prejudice reduction and has been used in the United States as a framework in multicultural education (e.g., Banks \& Banks, 2006; Bennett, 2007). Allport's theory posits that four necessary and positive conditions must be present during intergroup contact to reduce prejudice. Intergroup contact must occur in settings/spaces in which individuals and groups (1) have equal status; (2) share common goals; (3) must cooperate across groups to achieve goals; and (4) have the support of authority figures, whether that be teachers in classrooms or government institutions. Noting the continued segregation of schools in Romania (e.g., Hungarian only schools, special education only schools), social spaces that are explicitly structured to meet Allport's conditions are sometimes limited. Supportive teachers may fill the fourth goal by constructing opportunities that address the first three goals. Of course, it should be recognized that teachers operate within a realm of structural constraints that they have limited control of. These limitations should be taken into consideration when attending to their role in prejudice reduction.

More recently, the intergroup contact theory has been reformulated. Based on a meta-analysis of the relevant research on Allport's intergroup contact theory, Pettigrew (2004) and Pettigrew and Tropp (2006) propose the following revisions to Allport's theory. First, there is a small basic effect of intergroup contact in reducing prejudice. Second, the four necessary conditions promoted by Allport are actually positive facilitative factors that enhance the basic effect. However, these conditions/factors are not necessary to reduce prejudice. For example, and in general, any contact, even if it does not include all of Allport's four conditions, results in some prejudice reduction. Allport's conditions heighten the effect. Finally, for intergroup contact to actually increase prejudice, there must be strong negative factors operating in the situation, such as uncertainty, anxiety, or perception of a threat (Pettigrew \& Tropp).

Applying Allport's theory and its recent reformulation on the setting for this study, the following assumptions for Hungarians and Rroma interacting with the Romanian majority may be inferred. Referencing Allport's four conditions, 1) While Hungarians do not have full and equal access, they do have political participation and power; 2) Hungarians share common goals, particularly economic goals; 3) there is limited participation across groups (e.g., with the majority) to achieve their goals; and 4) there is external support from authorities. This includes the support of Hungary in land claims, as well as the institutional support of the Council of Europe and the European Union to reduce ethnic group tensions and support minority rights. The Rroma do not fare as well. Again, referencing Allport's four conditions, 1) the Rroma do not have political access or power in Romanian political institutions; 2) Romanians and Rroma do not share common political, economic, or social goals; 3 ) there is very little participation between Romanians and Rroma to achieve goals, in part evidenced by the higher levels of intolerance and social distance attitudes by Romanians toward Rroma that may indicate insecurity and anxiety; and 4) there is institutional support by the Council of Europe and the European Union to reduce ethnic group tensions and to specifically find ways to integrate the Rroma (e.g., Decade for Rroma Inclusion). 


\section{Conclusion}

Given the historical, political, and economic conditions in Romania and the accompanying context in which its citizens live, the struggle for equity and justice is difficult, just as it is in many other nations. However, Romania is working through numerous institutional systems to support these struggles. Continued institutional work and continued research into understanding the complexity of cultural attitudes, as well as the role of education and teacher education in addressing negative attitudes, should benefit all of the citizens of Romania as it moves into its new position in the European Union.

\section{References}

Ad Astra. (2007). Topul universităţilor din România - Clasamentul general - 2007 Retrieved February 27, 2008, [Online] Available: http://www.ad-astra.ro.

Adewuya, A. O., \& Makanjuola, R. O. A. (2004). Social distance towards people with mental illness amongst Nigerian university students. Social Psychiatry \& Psychiatric Epidemiology, 40, 865-868.

Arayici, A. (1998). The Gypsy minority in Europe - some considerations. UNESCO. Oxford, UK: Blackwell Publishers.

Banks, J. A. \& Banks, C.A.M. (2006). Multicultural education: Issues and perspectives. (6 ${ }^{\text {th }}$ ed.). Indianapolis, IN: Jossey-Bass.

Bennett, C. (2007). Comprehensive multicultural education: Theory and practice. Boston, MA: Pearson.

Bogardus, E. S. (1933). A social distance scale. Sociology and Social Research, 17, 265-271.

Butuca, A. (2003). Minorities, culture and education. Cultural Heritage and Contemporary Changes: Series IVA, Central and Eastern Europe, Volume 14 Retrieved February 2, 2007, [Online] Available: http://www.crvp.org/book/Series04/IVA- 14/contents.htm.

Cahn, C., Chirico, D., McDonald, C., Mohacsi, V., Peric, T., \& Szekely, A. (1998). Roma in The educational systems of Central and Eastern Europe. European Roma Rights Centre Report, Summer 1998.

Cajvaneanu, D. (2001). Does tolerance kill? The Hungarian minority in Romania: A case study. Romanian Journal of Political Science. INCOMPLETE

Chasteen, A. (2005). Seeing eye to eye: Do intergroup biases operate similarly for younger and older adults? International Journal of Aging and Human Development, 61(2), 123-139.

Chiva, C. (2006). Ethnic minority rights in Central and Eastern Europe: The case of the Hungarian "Status Law". Government and Opposition, 41(3), 401 - 421

Cozma, T., Cucos, C., \& Momanu, M. (2000). The education of Roma children in Romania: Description, difficulties, solutions. Intercultural Education, 1 (3), 281-288

Crowe, D. M. (1999). The Gypsies of Romania since 1990. Nationalities Papers, 27(1), 57- 
67

Crowe, D. M. (2008). The Roma in post-communist eastern Europe: Questions of ethnic conflict and ethnic peace. Nationalities Papers, 36(3), 521-552.

Damanakis, M. (2005). European and intercultural dimension in Greek education. European Educational Research Journal, 4(1), 78-88.

Dianu, T. (1997). Ethnic minorities in post-communist Romania: From rhetoric to integration. Field Report: Human Rights Brief. The Center for Human Rights and Humanitarian Law. Washington, DC. Retrieved from www.wcl.american.edu/hrbrief/v4i3/romani43.htm on $1 / 11 / 2007$.

Ellison, C. G., \& Powers, D. A. (1994). The contact hypothesis and racial attitudes among Black Americans. Social Science Quarterly, 75(2), 385 - 400.

Evans, G., \& Need, A. (2002). Explaining ethnic polarization over attitudes toward minority rights in Eastern Europe: A multilevel analysis. Social Science Research, 31, 653-680.

Filipescu, C. (2009). Revisiting minority integration in eastern Europe: Examining the case of Roma integration in Romania. Debate: Review of Contemporary German Affairs, 17(3), 297-314.

Forbes, H. D. (1997). Ethnic conflict: Commerce, culture, and the contact hypothesis. New Haven, CT: Yale University Press.

Gallagher, T. (1997). To be or not to be Balkan: Romania's quest for self-definition. Daedalus, 126(3), 63-84.

Gay, G. (2000). Culturally responsive teaching: Theory, research, and practice. New York: Teachers College Press.

Gogolin, I. (2002). Linguistic and cultural diversity in Europe: a challenge for educational research and practice. European Educational Research Journal, 1 (1), 123-138

Howard, G. (1999). We can't teach what we don't know: What teachers, multiracial schools. New York: Teachers College Press.

Ives, B., \& Howell, J. (in press). Romanian preservice educators' attitudes about disabilities. Journal of International Special Needs Education.

Jackson, J. W. (1993). Contact theory of intergroup hostility: A review and evaluation of the theoretical and empirical literature. International Journal of Group Tensions, 23, 43-65.

Johnson, C. (2002). Democratic transition in the Balkans: Romanian's Hungarian and Bulgaria's Turkish minority (1989 - 1999). Nationalism and Ethnic Politics, 8(1), 1-28.

Kruczek-Steiger, E., \& Simmons, C. (2001). The Rroma: their history and education in Poland and the UK. Educational studies, 27(3), 281- 290

Leeman, Y., \& Reid, C. (2006). Multi/intercultural education in Australia and the Netherlands. 
Compare, 36(1), 57-72.

Linden, R. H., \& Pohlman, L. M. (2003). Now you see it, now you don't: Anti-EU politics in central and southeast Europe. European Integration, 45(4), 311- 334.

Locke, S. (2005). Institutional, social and cultural influences on the multicultural perspectives of preservice teachers. Multicultural Perspectives, 7(2), 20-28.

Moldovan, B. A., and Lazar, D. T. (2009). Deficits and growth from Romania's perspective. Transylvanian Review of Administrative Sciences, (26E), 94-105.

Panagiotopoulos, C., \& Nikolaidou, M. (2007). At a crossroads of civilizations: Multicultural educational provision in Cyprus through the lens of a case study. Intercultural Education, 18(1), 65-79.

Patchen, M. (1999). Diversity and unity: Relations between racial and ethnic groups. Chicago: Nelson-Hall.

Pettigrew, T. F. (1998). Intergroup contact theory. Annual Review of Psychology, 49, 65-85.

Pettigrew, T. F., \& Tropp, L. R. (2000). Does intergroup contact reduce prejudice? Recent meta-analytic findings. In S. Oskamp (Ed.), Reducing prejudice and discrimination: Social psychological perspectives (pp. 93-114). Mahwah, NJ: Lawrence Erlbaum.

Pettigrew, T. F., \& Tropp, L. R. (2006). A meta-analytic test of intergroup contact theory. Journal of Personality and Social Psychology, 90(5), 751-783.

Pogany, I. (2006). Minority rights and the Roma of Central and Eastern Europe. Human Rights Law Review, 6 (1), 1-25

Ram, M. H. (2006). Democratization through European Integration: The case of minority rights in the Czech republic and Romania. Studies in Comparative International Development, 38 (2), 28-56.

Randall, N. H., \& Delbridge S. (2005). Perceptions of social distance in an ethnically fluid community. Sociological Spectrum, 25, 103-122.

Rapp, A. (1982). Prejudice and discrimination among community college students. Community College Social Science Journal, 4(3), 63-66.

Rat, C. (2005). Romanian Roma, state transfers, and poverty. International Journal of Sociology, 35(2), 85-93.

Schwellnus, G. (2005). The adoption of nondiscrimination and minority protection rules in Romania, Hungary, and Poland. In Schimmelfennig, F. \& Sedelmeier, U. (Eds.). The Europeanization of Central and Eastern Europe (pp. 51-70). Ithaca, NY: Cornell University.

Subedi, B. (2006). Preservice teachers' beliefs and practices: Religion and religious diversity. Equity \& Excellence in Education, 39, 227-238.

Tibbits, F. (2001). Prospects for civics education in transitional democracies: results of an 
impacts' study in Romanian classrooms. Intercultural Education, 12(1), 27-40.

Transue, J. E. (2007). Identity salience, identity acceptance, and racial policy attitudes: American national identify as a uniting force. American Journal of Political Science, 51(1), 78-91.

Universitatea Babes-Bolyai. (2007). About BBU, Retrieved February 27, 2008, [Online] Available: http://www.ubbcluj.ro.

Veres, V. (2006). Social stratification and ethnicity in Transylvania: How does social class matter? International Journal of Sociology, 36(1), 28-45.

Walker-Dalhouse, D., \& Dalhouse, A. D. (2006). Investigating white preservice teachers' beliefs about teaching in culturally diverse classrooms. The Negro Educational Review, 57(1-2), 69-85.

Westrick, J. M., \& Yuen, C. Y. M. (2007). The intercultural sensitivity of secondary teachers in Hong Kong: a comparative study with implications for professional development. Intercultural Education, 18(2), 129-145. 